Canadian

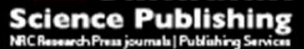

Canadian Journal of Civil Engineering Revue canadienne de génie civil

\title{
Effect of critical sub-system failures on the post-earthquake functionality of buildings: A case study for Montreal hospitals
}

\begin{tabular}{|r|l|}
\hline Journal: & Canadian Journal of Civil Engineering \\
\hline Manuscript ID & cjce-2015-0428.R1 \\
\hline Manuscript Type: & Article \\
\hline Date Submitted by the Author: & 18 -Jun-2016 \\
\hline Complete List of Authors: & $\begin{array}{l}\text { Youance, Suze; École de technologie supérieure, Génie de la construction } \\
\text { Nollet, Marie-José; Ecole de technologie supérieure, Genie de la } \\
\text { construction; } \\
\text { McClure, G.; Civil Engineering and Applied Mechanics }\end{array}$ \\
\hline Keyword: & $\begin{array}{l}\text { Buildings; seismic evaluation; performance-based earthquake engineering; } \\
\text { system reliability }\end{array}$ \\
\hline & \\
\hline
\end{tabular}

\section{SCHOLARONE"}

Manuscripts 
Effect of critical sub-system failures on the post-earthquake functionality of

\section{buildings: A case study for Montreal hospitals}

Suze Youance, ing.jr., $\mathrm{PhD}$.

Département de génie de la construction, École de Technologie Supérieure 1100 Notre-Dame Ouest,

Montréal, QC

Canada, H3C 1K3

Marie-José Nollet, ing., Ph.D.

Professeure

Département de génie de la construction, École de Technologie Supérieure 1100 Notre-Dame Ouest,

Montréal, QC

Canada, H3C 1K3

Ghyslaine McClure, ing., Ph.D.

Associate Provost

McGill University

James Administration Building, 845 Sherbrooke Street West

Montréal, QC

Canada, H3A 0G4

\section{Corresponding Author:}

Suze Youance, ing.jr., $\mathrm{PhD}$.

Département de génie de la construction, École de Technologie Supérieure 1100 Notre-Dame Ouest,

Montréal, QC

Canada, H3C $1 \mathrm{~K} 3$

Tél : 514-433-8899

Courriel : suze.youance.1@ens.etsmtl.ca 


\begin{abstract}
:
When an earthquake occurs, hospitals are expected to remain functional as they play a crucial role in emergency care operations. This ability to ensure the continuity of quality operations while ensuring the safety of occupants during and after an earthquake defines the concept of post-earthquake functionality. Hospital functionality relies on the good performance of a large number of critical sub-systems, components and equipment. Although the global seismic performance of building structures and their non-structural components was extensively observed in several post-disaster reconnaissance surveys, there is few and incomplete information on the effect of building and non-structural damage on post-earthquake functionality. The objective of this paper is to present a methodology for the assessment of post-earthquake functionality of existing Montreal hospitals using fault-tree analysis. The study shows that using specific and accurate information on the vulnerability and fragility of structural and critical non-structural components, a probabilistic index of post-earthquake functionality of the entire facility is computed which informs mitigation action for the critical failure processes through the system.
\end{abstract}

Keywords: Buildings; seismic evaluation; performance-based earthquake engineering; system reliability 


\section{INTRODUCTION}

Nowadays, the seismic performance expected from a building structure is linked to its use and occupancy as well as to the social, economic and operational impacts resulting from a poor performance (Gupta and Krawinkler 1999). As such, even when structural damage is minimal, some buildings become dysfunctional following moderate earthquakes. This is referred to as domino effect, technological failure or more directly, loss of functionality.

Oddly enough considering the main goal of building codes, these concepts are relatively new in earthquake structural engineering. They are based on the analysis of the consequences of local failure of critical operational and functional components (OFCs) in the system. Experiences from large earthquakes such as in Northridge, California (January $\left.17^{\text {th }}, 1994-M_{\mathrm{w}} 6.7\right)$, Kobe, Japan (January $16^{\text {th }}, 1995-\mathrm{M}_{\mathrm{w}} 6.9$ ), Kocaeli, Turkey (August $17^{\text {th }}, 1999-\mathrm{M}_{\mathrm{w}} 7.6$ ) and Chi Chi, Taiwan, China (October $20^{\text {th }}, 1999-\mathrm{M}_{\mathrm{w}} 7.6$ ), have highlighted the fact that the post-earthquake functionality of hospitals largely depends on the good performance of its non-structural components and equipment (Myrtle et al. 2005). In each of these disasters, and even in more recent events, health care facilities had to be evacuated (Davidovici 2007; EERI 2009, 2010; Myrtle et al. 2005; NCREE 2010).

These observations initiated new research towards the understanding and improvement of seismic behaviour of OFCs. These include seismic assessment and conducting experimental investigations of OFCs, the development of database and provisions or guidelines for seismic design and seismic risk reduction of OFCs (PWGSC 1995; Soong 
et al. 1999; Chong and Soong 2000; Filiatrault et al. 2003; CSA 2014). From a postearthquake functionality point of view, the focus has been made on a better understanding of damage propagation within a system and to improve codes and construction standards, especially in high seismic risk regions (Johnson et al. 1999; Myrtle et al. 2005; Nuti and Vanzi 1997; Porter et al. 2006; Scawthorn 2011; Shinozuka et al. 2004; Yavari et al. 2010).

In Eastern Canada, the Saguenay earthquake $\left(1988, \mathrm{M}_{\mathrm{w}}\right.$ 5.9) is one of the largest and most damaging event to have occurred in recent decades; damage reports on hospital buildings from this event are also the only ones documented in Canada, despite a higher seismic hazard on the West Coast (Hanna 1993). Although no severe structural damages (except to the Montreal East City Hall building that suffered foundation failure) or major fires were reported, this earthquake provided an excellent opportunity to investigate the "serviceability performance" of critical buildings in the event of stronger earthquakes (Mitchell et al. 1990). Observations from damage reconnaissance teams in hospital buildings highlighted the following: 1) the abundance of damaged unreinforced masonry (URM) walls poorly fastened to the structures, 2) the vulnerability of operational systems dedicated to essential services: communication and water pipes systems and the managing rescue and evacuation operation and 3) the presence of local site conditions that tended to amplify shaking levels and structural damage. According to the detailed analysis of building damage, 36 hospitals were affected at a distance up to $350 \mathrm{~km}$ from the epicenter (Paultre et al. 1993). Although most of the available damage data remains qualitative and limited, these observations highlight the vulnerability of existing buildings and indicate potential dysfunction of post-disaster buildings for moderate seismic events 
due to damaged operational and functional components. As summarized in Table 1, small horizontal accelerations were recorded in Quebec city, but significant non-structural damage did occur in two hospitals built on soft soil (Mitchell et al. 1990).

Recent changes to the seismic provisions of the National Building Code of Canada (NBCC 2010) provide more explicit requirements in relation to the performance of postdisaster buildings (IRC-CNRC 2010). Immediate occupancy of these buildings is mandatory for rare earthquakes with a hazard level of $2 \%$ in 50 years. Therefore, it can be assumed that for more frequent events (10\% in 50 years), the full functionality should be maintained. In both cases, the structure shall retain most of its initial strength and stiffness, while essential non-structural components and critical systems could suffer only minor or no damage. For non-structural components in existing and new buildings, the Canadian standard CSA-S832-14 (CSA 2014) complements the NBCC clauses that apply to new buildings only, and suggests a methodology for seismic risk assessment of individual OFCs. The OFC risk assessment procedure accounts for interdependencies between the building structure, the building content and its non-structural components and subsystems, and their interfaces with lifelines.

\subsection{Evidence of interdependencies in hospitals}

A hospital is a complex and highly interactive system of structural components, operational and functional equipment and personnel providing services. Figure 1 reflects this interactivity/interdependency in a post-earthquake functionality context. The overall reliability of the hospital system is determined by: 1) the seismic vulnerability assigned to each OFC; 2) the seismic vulnerability of the structure and its vertical and lateral load 
resisting systems and; 3) the vulnerability of its various utility interfaces (electricity, water, gas, telecommunication, etc.), which are all directly influenced by seismic hazard and geotechnical site effects. The dashed line in the figure represents the interaction of seismic performance involving the building structure, the OFCs and their subsystems and the service lifelines and interfaces. The interaction between the different components is complex and the system functionality cannot be achieved by a simple sum of subsystem vulnerability or component indices.

\subsection{Research Significance}

The main objective of this study is to develop a methodology to assess the seismic risk of a health care centre (Montreal hospital), with the consideration of the interaction between various physical elements. The study describes the concept of system interaction in hospitals along with the Fault-Tree Analysis (FTA) method that is used to collect and analyse data. The effect of interactions between critical sub-systems on the postearthquake functionality of the whole is illustrated by a case study of two essential hospital systems: Heating, ventilation and air conditioning (HVAC) and life support systems. The seismic risk for independent critical health care facilities is assessed through a post-earthquake functionality index giving valuable insights on salient risk contributors and eventual mitigation action. 


\section{RISK ANALYSIS FRAMEWORK FOR COMPLEX SYSTEMS}

\subsection{Methodology}

To quantify the consequence of failure, the authors proposed an iterative approach: 1) a qualitative phase in order to conceptualize the hospital systems using fault tree model, and 2) a quantitative phase based on a combination of existing procedures and methods:

- The seismic vulnerability of the buildings is evaluated from the updated version of the NRC-92 procedure (Rainer et al. 92);

- The seismic risk associates to the OFCs is evaluated according to the CSA 2014 methodology (CSA 2014);

- The probability of damage to OFCs is estimated from fragility functions developed by HAZUS (NIBS 2013);

- The probability of failure within a system is computed using fault tree analysis (MIL-STD-1629A 1980; Vesely et al. 1981).

\subsection{Infrastructure interactions and complexities}

In a theory of "normal accidents", Perrow (1984) suggested that systems of high complexity, coupling technology and organization are subjected to cascading failures. Considering the widespread presence of technology in society's common operations and essential infrastructure, this notion has evolved and expanded to various fields such as economy or national security (Dhillon 1999). In this perspective, Rinaldi et al. (2001) proposed a conceptual framework for addressing infrastructure interactions and complexities in terms of six "dimensions", to clarify the various aspects of interactions within complex systems (See Table 2). The interdependencies are defined by 
bidirectional relations between infrastructures or as intrinsic relations within a given infrastructure. The problem of complex system analysis and infrastructure interactions can also be defined in the form of a set of questions as proposed by Limnios (1991). The proposed framework for the analysis of hospital's complex systems follows these concepts and identifies global objectives and models for risk analysis based on the fact that seismic performance of components depends on their vulnerability and fragility (Table 2).

To determine the reliability of the system, one needs to assess its failure scenarios and determine the influence of a given component state or a default type on the whole. The main challenge is then to conceptualize a functional hospital system that can accurately represent the component and sub-system interdependencies, the interface complexities, the component and sub-system failure modes and the associated losses or consequences. The proposed approach is to construct the functional hospital system using Fault Tree Analysis (FTA) that is commonly used in risk analysis of complex systems modelled by random variables (MIL-STD-1629A 1980; Vesely et al. 1981).

A fault tree is a logical graph representing the various combinations of basic failure/malfunction events susceptible to occur in a system. The fault tree depicts the relationship between the Output (higher event) and Input (lower event) as a Boolean gate (.AND. / .OR.) in order to evaluate the probability of failure of the higher event. When the first failure (lower event) occurs, an .AND. gate represents relationships between all the input faults in such way that the system will automatically rely on the next input event in the row to survive, whereas an .OR. gate indicates that the system will fail. The .AND. 
gate therefore expresses a more robust and redundant system. This deductive analysis from the higher event will proceed until reaching all lower event or individual components or equipment failure modes. Moreover, FTA offers modularity and flexibility that enable specific accommodations to the required scenarios, such as change in the components or sub-systems interdependency or the possibility of using another probability theory.

\subsection{Quantitative analysis methodology}

Subsequent to the qualitative process of mapping the system FTA, a quantitative analysis can proceed by defining a Priority Risk Index (PRI) for each lower event. This is called Failure Modes, Effects \& Criticality Analysis (FMECA), aiming to identify failures that have significant (or undesirable) effects on system performance. As expressed by Equation 1, PRI is the simple product of a risk level (SRI, Seismic risk index in the present application) and the probability $(\mathrm{P})$ of reaching or exceeding a given damage level or failure. This application is more inherently simple than usual FMECA as the failures will all be initiated from damage due to an earthquake.

\section{[1] $\quad \mathrm{PRI}=\mathrm{SRI} \times \mathrm{P}$}

The resulting $P R I_{i}$ for each lower event $i$ is then injected into the fault tree to obtain the final post-earthquake functionality index $\left(P F I_{j}\right)$ of a system $j$ by algebraic calculation rules. These rules highlight the weaknesses in systems as the fault tree represents all possible failure paths or direct effects of damage to components (Equations 2 and 3). The 
proposed methodology allows to quantify the consequences of interdependent failures from individual component dysfunctions.

[2] .AND. gate : $\mathrm{PFI}_{\mathrm{j}}=\mathrm{PRI}_{1} \times \mathrm{PRI}_{2} \times \ldots \times \mathrm{PRI}_{\mathrm{i}}$

[3] .OR. gate : $\quad \mathrm{PFI}_{\mathrm{j}}=1-\left(1-\mathrm{PRI}_{1}\right) \times\left(1-\mathrm{PRI}_{2}\right) \times \ldots \times\left(1-\mathrm{PRI}_{\mathrm{i}-1}\right)$

The PFI has an optimal value of zero, which corresponds to a system fully functional or in which the top event has an ideal zero probability of occurrence. For example, low PFIs typically indicate optimal base event conditions with a low probability of damage or high redundancy.

The implementation of this quantitative post-earthquake functionality analysis for Montreal hospital buildings relies on the construction of a reliable database on seismic vulnerability information to define the risk level, SRI. The probability of failure P of nonstructural components could be obtained from fragility curves expressed in terms of spectral acceleration or spectral displacement, as appropriate to their failure modes.

\section{OVERVIEW OF MONTREAL HOSPITALS AND SEISMIC VULNERABILITY CONTEXT}

The portrait of Montreal hospitals shows a wide range of building types housing various critical services, local site conditions and seismic characteristics. In an Eastern North American context where observed earthquake damage data are scarce, those factors have to be combined to create damage models in the perspective of post-earthquake 
functionality assessment. According to the last annual report of Montreal's Health and Social Services Agency, the Montreal Island population, estimated to 1.9 million, received health care services from 81 institutions and around 400 facilities and service points distributed throughout its $499 \mathrm{~km}^{2}$ territory (ASSSM 2014). Among those institutions, 31 are categorized as hospitals, i.e. general and specialized or ultraspecialized care facilities offering emergency services, nursing, paediatric and mental health care and other services including medical imaging, nuclear medicine or rehabilitation services: these are mapped on Fig.2.

These hospitals are generally composed of several buildings that are structurally independent, i.e. separated by structural joints. In Montreal, half of them have been built between 1950 and 1970. They are pre-code in terms of seismic design according to NBCC. Typically they consist in large buildings of low to medium height (up to 14 stories) with few exceptions (see Fig. 2). The most common structural systems are steel braced frames, steel frames with masonry infills and reinforced concrete frames with masonry infills. Individual buildings are usually of rectangular footprint with few vertical or horizontal irregularities. Heavy load-bearing masonry walls are used in the oldest constructions, built before 1920 ( $22 \%$ of buildings): These buildings will be closed down and their services relocated in new buildings under construction. Two facilities, Montreal General Hospital (MGH) and Rivière-des-Prairies Hospital (RDPH), have been retained as case studies to develop a database on seismic vulnerability with three main damage factors: 1$)$ seismic hazard ( $10 \%$ and $2 \%$ in 50 years occurrence), 2$)$ site category (stiff to soft soil, site classes A to E according to NBCC), and 3) building fundamental period. 
MGH is a designated Adult Trauma Centre and RDPH is specialized in Pediatric and Adolescent psychiatric care, therefore both hospitals bring specific challenges related to post-seismic functionality. Hospital building managers are aware of this complexity and have set up management systems to detect hazard, communicate alerts, and respond promptly and efficiently. Main critical OFC systems are designed to be redundant and secondary systems provide additional or more specific services. For example, hospitals typically use multiple sources of energy or connections to water or power supply utility network with backup systems for fast recovery in case of interface or external failure. Internally, there is redundancy in almost all of the essential OFCs such as power generators, boilers, filter systems, pumps for medical air production, etc. to ensure continuity of operations in case of a component dysfunction during normal building operations. Fault trees of the analyzed systems are developed in section 4.

With around one million square feet, the MGH operational area is about twice the RDPH's. As illustrated in Figure 3, both hospitals are comprised of several blocks, typically steel braced frames with uniform plan joining at right angles, simple façades and flat roofs. Diagonal bracings are located at the perimeter of each block and are made of symmetric steel plates and angles.

\section{DEFINITION OF RISK LEVEL (SRI) FROM SEISMIC VULNERABILITY DATA}

As a first step, a qualitative risk assessment process, based on a visual in-situ inspection of ten MGH and RDPH buildings, has been conducted to collect information on structures and non-structural components being part of 17 critical systems. The structural 
inspection followed the procedure for rapid visual screening of buildings described in NRC-92 and updated to the more recent seismic provisions of NBCC 2005 (Rainer et al. 1992, Saatcioglu et al. 2013). The non-structural inspection is carried out in accordance with the parametric procedure described in CSA-S832-14 Seismic risk reduction of operational and functional components (OFCs) of buildings" (CSA 2014). The results are expressed by a Seismic Risk Index (SRI) for each building and each OFC.

Collected data were used to generate samples of 76 cases for the structure and 4044 cases for the OFCs or 224 critical systems. The SRI serves to estimate the seismic vulnerability as function of each damage factor or in other words, is an indication of potential structural or non-structural damage that could hinder the global functionality of hospitals at the urban scale of Montreal Island. This database encompassed the SRI values obtained for the hospital buildings and OFCs that were inspected.

The two sets of data are statistically analysed to identify their main trends and define four levels of risk (slight to very high). The definition of risk levels harmonizes the overall methodology with the damage levels (from slight to complete) considered in fragility functions or probability of damage $(\mathrm{P})$.

The risk levels and their relative threshold values for the SRI index proposed in Table 3, have been defined in accordance with CSA-S832-14 and expert judgement within the range of the calculated SRI values. The normalized rank highlights the high seismic vulnerability of the last two classes for which mitigation measures or further evaluation are mandatory. 
SRI indices for the structure were generated from the parametric combinations that could trigger seismic deficiency, as follows: (i) three groups of buildings according to their fundamental period ( $\mathrm{T} \leq 0.2 \mathrm{~s} ; 0.2 \mathrm{~s}<\mathrm{T} \leq 0.5 \mathrm{~s} ; \mathrm{T}>0.5 \mathrm{~s}$.); (ii) five seismic site classes, and; (iii) the presence of structural irregularities. The maximum SRI value generated is 63 and represents an irregular structure with a fundamental period of $0.5 \mathrm{~s}$ and located on a site class E (soft soil). The minimum SRI value of 3.0 was found to be larger than the threshold value for low risk $(\mathrm{SRI} \leq 2)$ as illustrated in Figure 4, a reflect of the age of the buildings used to build the database (pre-code buildings). The dashed line shows the threshold of moderate seismic risk level to the structure. The global distribution of SRI index confirms the importance of structural irregularities and site amplification effects on the seismic vulnerability.

The SRI for non-structural components is obtained for each OFC from the risk index (R) defined in CSA-S832-14 as the product of a vulnerability index score (V) and a consequences index score (C). SRI index values for OFCs were generated by varying the parameters of building characteristics, site categories and ground motion characteristics, for a total of 4044 cases. The statistical analysis of these results is summarized in Figure 5 with the dashed line showing the moderate risk level threshold (SRI=64). It is seen that the first two levels of risk (slight and moderate) are obtained in most cases $(88 \%$ of the database), for either all site categories for a $10 \%$ in 50 years hazard or site A and B for a $2 \%$ in 50 years event. However, the limit of the high risk category was lowered to 86 instead of 128 as recommended by the standard CSA-S832-14, to highlight the very high risk associated with site category E (or upper $5 \%$ extreme values). 


\section{DEFINITION OF PROBABIBLITY OF DAMAGE (P) FROM FRAGILITY DATA ANALYSIS}

Fragility curves refer to mathematical functions describing the probability of reaching or exceeding a given level of damage state (DS) related to a given level of ground shaking (or ground failure). Equation 4 assumes that seismic demand is represented by the spectral displacement $S_{d}$, a valid assumption for the building structure and displacementsensitive OFCs:

$$
\mathrm{P}\left[\mathrm{DS} \mid \mathrm{S}_{\mathrm{d}}\right]=\phi\left[\frac{1}{\beta_{\mathrm{DS}}} \ln \left(\frac{\mathrm{S}_{\mathrm{d}}}{\overline{\mathrm{S}}_{\mathrm{d}, \mathrm{DS}}}\right)\right]
$$

In this equation, $S_{d, D S}$ is the median value of the spectral displacement for specified DS, $\beta_{D S}$, the standard deviation of the lognormal distribution and $\phi$ represents the lognormal cumulative standard normal distribution. Discrete probabilities of damage are used directly as inputs to induced physical damage into systems of components and the structural system (NIBS 2003).

Extensive literature covers the development of those parameters from empirical, analytical or mixed approaches. Among them, the HAZUS methodology proposed fragility values for $S_{d, D S}$ and $\beta$ DS for a large range of structural building types modelled as an equivalent single-degree-of-freedom model (ESDOF), acceleration-sensitive and displacement-sensitive non-structural components (NIBS 2003). HAZUS values are frequently used to define fragility curves when specific regional data are sparse, as is the case for Montreal. Although fragility data in HAZUS were developed for buildings in the 
US, hospital building's structural types and occupancy class are compatible with the description given in HAZUS. At this stage of the research, the assumption that HAZUS's fragility data could be used in the context of Montreal is considered reasonable. However, authors are aware of this limitation which highlights the need for research and development of specific fragility data for the Canadian context.

For both structural and non-structural components, fragility values are given in terms of equivalent peak ground acceleration (PGA) or spectral seismic demand (pseudoacceleration $S_{a}$ or spectral displacement $S_{d}$ ), depending on the damage mode of the component. This approach is therefore well suited to quantify the post-earthquake functionality of few specific buildings and a large number of non-structural components. However, a drawback of using HAZUS fragility values is that the probability of damage for non-structural components is only defined in terms of total drift of the building (Eq. 4), which is not a correct indicator for components that are sensitive to inter-story drift or accelerations, or both. More specific fragility information should then be used to better reflect this type of vulnerability.

The model parameters used to build the ESDOF model of the studied buildings are extracted from ambient vibration measurements, and period values were found to vary from $0.16 \mathrm{~s}$ to $1.2 \mathrm{~s}$. Seismic demand indicators at an equivalent height, $\mathrm{S}_{\mathrm{a}}$ and $\mathrm{S}_{\mathrm{d}}$, are computed directly from the Uniform Hazard Spectra for Montreal and for both $2 \%$ and $10 \%$ in 50 years occurrence. Figures 6 and 7 provide the fragility curves obtained for both drift and acceleration sensitive OFCs and for four damage states: slight, moderate, extensive and complete. A similar procedure has been followed for the structure seismic fragility. Values (median and deviation) from HAZUS take into account: 1) seismic 
design level (Low level), 2) building type (Steel moment frame S1), 3) building height (Low, Medium, High), 4) facility classification (Essential facilities) and 5) sensitivity (NIBS 2003). It should be noted that for acceleration-sensitive OFCs, there is no significant variation in the fragility with the height of the structure (see Figure 7).

As mentioned previously, one specific seismic demand (OFC or building) is related with four values of P (Figure 7), which will be reflected in the distribution of system PFI indices. The levels of risk for structural and non-structural SRI defined in the previous section, as well as the fragility information will be used in the following section to illustrate the application of the proposed methodology to calculate a PFI index for critical systems using fault-tree analysis.

\section{CASE STUDY}

This section presents an overview of the reliability analysis of two critical functional systems: 1) HVAC (Heating, ventilating, and air conditioning) and 2) life support including medical gases production, as built at the Montreal General Hospital. The PFI is obtained for a structure having a fundamental period of $0.5 \mathrm{~s}$, a slight probability of damage, and a seismic hazard level of $2 \%$ in 50 years occurrence. The risk index (PRI) Equation 1, is computed for each component at the base of the fault tree (event, EVi) considering different seismic hazard and site conditions. The upward computation of PFI is then carried out using Boolean algebra equations 2 and 3, as illustrated on the system fault trees of Figures 8, 9 and 11 built with Isograph (Isograph Ltd. 2011). In order to have the complete PFI index distribution for this building, the same procedure has to be applied to the other damage levels (moderate, extensive and complete). 


\subsection{HVAC system}

HVAC systems in hospitals are required to achieve a variety of critical functions with high levels of performance. Examples of such functions include maintaining optimal levels of air quality, humidity and heat to ensure infection control; special care is needed for hazardous substances used in medical treatments, which require air exchange, treatment and complex filtering. HVAC systems are also key to fire detection and space pressurization with exhaust devices.

Montreal hospital HVAC systems typically include a central heating system and air conditioning systems and ventilation units according to serviced areas (corridors, operating room, emergency, magnetic resonance, critical areas, etc.). Moreover, given the importance of the good performance of the HVAC system to maintain continuous hospital functionality, it is also connected to emergency power supply sources. The HVAC system fault-tree includes the following sub-systems (cf. Figure 8):

- The central heating system including OFC unit that is necessary for the production of heat or steam supplemented in some cases by storage tanks and hot water reservoirs for domestic needs (sterilization and humidification). The fault tree identifies two main sub-systems: sub-system 1 - heat and steam production system (Gate 1, GT1), and sub-system 2 - hot water production (Gate 2, GT2). Under each gate a lower event (EV1 to EV11) identifies a specific OFC unit.

- The interface system to buildings could be represented by supply pipes (drinkable water pipes, shut-off valves or check valves, etc.) connected to the main municipal water supply network. Seismic requirements for shut-off valves or check valves for supply pipes vary, somehow, from a region to another (FEMA 
2011). Seismic design guidelines for these components, and in particular for supply pipes containing hazardous materials, lack a strong rational basis due to the scarcity of research data, as indicated in CSA-S832-14.

- HVAC systems use air conditioning to remove heat from one area and ventilation to maintain a comfortable environment usually through cooling towers and aircooled condensers using a refrigerant (mainly glycol) and evaporative condensers in some cases integrate with a cooler (see Figure 9). The fault tree of a typical air conditioning system identifies the top event (TP1) as depending of two main subsystems: 1) the chiller system (Gate 1, GT1), 2) the air treatment system (Gate 2, GT2), 3) the distribution system (Gate 3, GT3), and 4) the water pipe system (EV1). Under each gate, a lower event (EV2 to EV9) identifies a specific OFC unit such as chillers, filters, redundant power source, control equipment and piping systems. The complexity of the control system depends on the sophistication of the many subsystems to be monitored. Figure 10 shows examples for domestic water supply and air filter systems.

\subsection{Life support system}

Figure 11 shows the fault tree of a life support system including systems for in-situ production of medical gases (GT1), physiotherapy, intensive care and decontamination equipment (GT2 to GT4). The main distribution network for medical gas is composed of a set of three sub-systems (including pipe systems) and their control: 1) centrifugal compressor for medical air production (GT5), 2) vacuum pumps for suction gas production (GT6), and 3) high pressure portable cylinders (EV1). At the end of the distribution network or in medical care areas, power modules for medical gases must pass 
stress tests to dynamic and static forces as required by standards; they are not considered in this analysis.

Single OFCs in subsystems GT2 to GT4 are mainly mobile devices (gas cylinders) that could pose life safety issues as they can be stored with inadequate restraints. All OFCs at the base are considered acceleration-sensitive (Figure 7).

\section{DEAGGREGATED VALUES OF POST-EARTHQUAKE INDEX}

\subsection{Extended PFI values at urban Montreal scale}

Figures 12 to 14 present PFI values obtained for the four levels of damage considered (slight, moderate, extensive and complete) as function of : (i) seismic hazard (10\% and $2 \%$ in 50 years occurrence); (ii) site category (stiff to soft soil, A to E), and; (iii) building fundamental period T. These figures illustrate the PFI distribution for different buildings and cumulative damage level, for rapid identification of conditions that hinder hospital functionality. From this deaggregation analysis, the following observations can be made:

- As expected, structural PFI is directly proportional to the vulnerability of the building and the probability of damage $(\mathrm{PFI}=\mathrm{PRI})$, and structures on soft soils are the most affected. But while no structural PFI reveals significant risk of complete damage (Figure 12), OFC systems can experience damage from slight to complete. This emphasizes the importance of insuring OFC functionality even for low seismic hazard. Figure 12 is scaled at $1 / 10$ compared to Figures 13 and 14 related to PFI for OFC.

- For both structural and non-structural systems, PFI values show peaks for buildings on sites $\mathrm{C}$ to $\mathrm{E}$; particularly in taller buildings with fundamental period 
higher than $1 \mathrm{~s}$. Mitigation measures are therefore mandatory for these high PFI values.

- Exclusively comprised of acceleration-sensitive components, the analysis indicates that the life support system has the highest PFI. In case of a $2 \%$ in 50 years earthquake and a low-rise building (itself sensitive to acceleration), the life support system could present failure for all sites (see figure 14). However, in a more specific study, PFI values shall be less since acceleration at equivalent roof level is used in the generic evaluation.

- The proposed methodology can be used in a screening process as the dysfunction depends jointly on the likely occurrence of an earthquake, the inherent structural vulnerability and the fragility states considered.

\subsection{Interpretation criteria}

The probability of damage $\mathrm{P}$ (from slight to complete damage) alongside the risk levels SRI (from slight to very high) are grouped into a risk matrix to develop PFI interpretation criteria (Figure 15). It is seen that to achieve hospital required levels of performance; the only acceptable combination is slight damage with slight risk. Obviously, unacceptable performance will occur when considering a probability of complete damage and a very high seismic risk. The matrix form facilitates risk interpretation to support decision making for mitigation action.

More specifically, the performance of the studied systems can be interpreted and as follows:

- For the HVAC system exposed to a seismic hazard of $2 \%$ in 50 years, $95 \%$ of 
OFCs have a moderate risk when on site Class A, whereas $75 \%$ of OFCs are at very high risk when on site Class E. The expected performance levels are, respectively, immediate occupancy and unacceptable performance. For a hazard level of $10 \%$ in 50 years, the PFI values are all less than 0.4 and the PRI indices are concentrated in areas of low or moderate damage, suggesting an acceptable level of performance of either complete functionality or immediate occupancy;

- The life support system shows a uniform distribution of high PFIs (close to one) for a seismic hazard of $2 \%$ in 50 years. This could be attributed to the fact that unrestrained portable components reach high or very high risk level index (SRI). Post-earthquake functionality will be highly hindered with life safety challenges posed by such components.

- Finally, the expected performance of critical systems in hospital buildings on Montreal sites of class $\mathrm{D}$ or $\mathrm{E}$ will be minimally in the life safety range for a seismic hazard of $2 \%$ in 50 years.

\section{CONCLUSIONS}

The predictive approach for the assessment of post-earthquake functionality of hospital systems mainly focuses on modelling and on risk assessment of non-structural components. To illustrate the approach and assess how component failures propagate through a system, two case studies of OFC systems were analysed and discussed. According to the proposed methodology, the risk level is considered in a unified way for all types of non-structural components and the structure, through indices obtained from the application of known and largely used seismic evaluation procedures as well as fragility information. The final post-functionality index (PFI) resulting from the 
procedure takes into consideration interdependencies within the systems and with the structure, as reflected in fault trees. Data collection on specific components (4044 OFCs) and buildings (76 units) reduced the uncertainties associated with the computation of the PFI index. It appears that the proposed methodology gives an accurate picture of the earthquake survivability of Montreal hospitals and consequently can inform decisions pertaining to mitigation. However, further research is needed to improve the information on the probability of damage to operational and functional components of buildings.

\section{AKCNOWLEDGEMENT}

The financial support provided by the Natural Sciences and Engineering Research Council of Canada (NSERC) in the form of a Strategic Research Project Grant, and the Centre d'étude interuniversitaire des structures sous charges extremes (CEISCE) are gratefully acknowledged. The authors wish to thank the MGH and RDPH hospital technical Services Division.

\section{NOTATION}

DS: Damage state

IS: Structural index according to NRC-92

PFI : Post-earthquake functionality index

PRI : Priority risk index

SRI : Seismic risk index

P : Probability of damage value

V, and C: Vulnerability and Consequence indices according to CSA 2014

$S_{a}:$ Spectral acceleration

$S_{d}:$ Spectral displacement

$S_{d, D S}$ : Median value of the spectral displacement 
$\mathrm{T}_{\mathrm{a}}$ : Fundamental period

$\beta_{D S}$ : Standard deviation of the lognormal distribution

$\phi$ : Lognormal cumulative standard normal distribution 


\section{REFERENCES}

ASSSM. 2014. Vivre une île en santé, Rapport annuel de gestion 2013-2014. Montreal: Agence de la santé et des services sociaux de Montréal.

CSA. 2014. Seismic risk reduction of operational and functional components (OFCs) of buildings. Mississauga: CSA Group.

Chong, W.H. and Soong, T.T. 2000. Sliding fragility of unrestrained equipment in critical facilities. Coll. Technical Report MCEER-00-0005. Buffalo: Multidisciplinary Center for Earthquake Engineering Research, 103 p.

Davidovici, V. 2007. Conception et réalisation d'hôpitaux en zone sismique.

Dhillon, B.S. 1999. Design reliability fundamentals and applications. Boca Raton, FL: CRC Press.

EERI. 2009. The Mw 7.6 Western Sumatra earthquake of September 30, 2009. In EERI Special Earthquake Report - Learning from earthquake. Oakland: Earthquake Engineering Research Institute.

EERI. 2010. The Mw 8.8 Chile earthquake of February 27, 2010. In EERI Special Earthquake Report - Learning from earthquake. Oakland: Earthquake Engineering Research Institute.

Filiatrault, A., Aref, A., Bruneau, M., Constantinou, M., Lee, G., Reinhorn, A., and Whittaker, A. 2003. MCEER's Research on The Seismic Response Modification of Structural and Non-Structural Systems and Components in Hospitals. Coll. Seismic Retrofit of Acute Care Facilities, $25 \mathrm{p}$

Gupta, A.K., and Krawinkler, H. 1999. Seismic demands for the performance evaluation of steel moment resisting frame structures. Edited by Stanford University. 
Stanford, CA: The John A. Blume Earthquake Engineering Center, Department of Civil and Environmental Engineering, Stanford University.

Hanna, J. A. 1993. Disaster Planning for Health Care Facilities. CMAJ: Canadian Medical Association Journal no. 148 (2):134.

IRC-CNRC. 2010. Code national du bâtiment. Ottawa: Institut de recherche en construction, Conseil national de recherches du Canada.

Reliability Workbench 11.0.27.0. Isograph Ltd., California.

Johnson, G.S., Sheppard, R.E., Quilici, M.D., Eder, S.J., and Scawthorn, C.R. 1999. Seismic Reliability Assessment of Critical Facilities: A Handbook, Supporting Documentation, and Model Code Provisions. In Technical Report MCEER, edited by EQE International Inc. Buffalo, NY: Multidisciplinary center for earthquake engineering research (MCEER).

LeBoeuf, D., and Nollet, M. J. 2006. Microzonage et vulnérabilité sismique de la ville de québec Ville de Québec, (QC): Université Laval, École de technologie supérieure.

Limnios, N. 1991. Arbres de défaillance, Série Diagnostic et Maintenance. Paris: Hermès.

MIL-STD-1629A. 1980. Procedures for performing a failure mode, effects and criticality analysis. Washington D.C. : U.S. Department of Defense.

Mitchell, D., Tinawi, R., and Law, T. 1990. Damage caused by the November 25, 1988, Saguenay earthquake. Canadian Journal of Civil Engineering no. 17 (3):338-365.

Myrtle, R.C., Masri, S.F., Nigbor, R.L., and Caffrey, J.P. 2005. Classification and prioritization of essential systems in hospitals under extreme events. Earthquake Spectra no. $21(3): 779-802$. 
NCREE. 2010. The $M_{L} 6.4$ Taiwan Earthquake of March 04, 2010. In Reconnaissance activities, edited by LFE: National Center for Research on Earthquake Engineering.

NIBS. 2003. HAZUS-MH MR4: Multi-hazard Loss Estimation Methodology Earthquake Model Technical manual. Washington, D.C, USA: Federal Emergency Management Agency, National Institute of Building Sciences, Department of Homeland Security, Emergency Preparedness and Response Directorate.

Nuti, C., and Vanzi, I. 1997. Seismic safety of Abruzzo hospital system. Paper read at 11th European Conference on Earthquake Engineering at Rotterdam.

Paultre, P., Lefebvre, G., Devic, J.-P., and Côté, G. 1993. Statistical analyses of damages to buildings in the 1988 Saguenay earthquake. Canadian Journal of Civil Engineering no. 20 (6):988-998.

Perrow, C. 1984. Normal accidents: Living with High-Risk Technologies: New York Basic Books.

Porter, K.A., Krishnan, S., and Xu, X. 2006. Analysis of Simultaneous Operational Failure of Critical Facilities due to Earthquake, for a California Utlity. edited by California Institute of Technology. Pasadena, California: California Institute of Techonology.

PWGSC. 1995. Guideline on seismic evaluation and upgrading of non-structural building components. Public Works and Government Services Canada, Ottawa, Ontario.

Rainer, J.H., Allen, D.E., and Jablonski, A.M. 1992. Manuel de sélection des bâtiments en vue de leur évaluation sismique. NRCC 36943F. Ottawa: Institut de recherche en construction - Conseil national de recherches Canada, 90 p. 
Rinaldi, S. M., Peerenboom, J. P., and Kelly, T. K. 2001. Identifying, understanding, and analyzing critical infrastructure interdependencies. Control Systems, IEEE no. 21 (6):11-25.

Saatcioglu, M., Shooshtari, M., and Foo, S. 2013. Seismic screening of buildings based on the 2010 National Building Code of Canada. Canadian Journal of Civil Engineering, vol. 40, $\mathrm{n}^{\mathrm{o}} 5$, p. 483-498.

Scawthorn, C. 2011. Water supply in regard to Fire Following Earthquake. Berkeley: Pacific Earthquake Engineering Research Center, Seismic Safety Commission

Shinozuka, M., Chang, S.E., Cheng, T-C., Feng, M., O’Rourke, T. D., Saadeghvaziri, M.A., Dong, X., Jin, X., Wang, Y., and Shi, P. 2004. Resilience of integrated power and water systems. In, 65-86. Citeseer.

Soong, T.T., Kao, A.S., and Vender, A. 1999. Non-structural damage database. MCEER99-0014. Buffalo, N.Y.: Multidisciplinary Center for Earthquake Engineering Research (MCEER).

Vesely, N.H., Goldberg, F.F., Roberts, N.H., and Haasl, D.F. 1981. Fault tree handbook. Washington, DC: Systems and Reliability Resarch, US Nuclear Regulatory Commission, Office of Nuclear Regulatory Research.

Yavari, S., Chang, S. E., and Elwood, K. J. 2010. Modeling Post-Earthquake Functionality of Regional Health Care Facilities. Earthquake Spectra no. 26 (3):869. 


\section{LIST OF TABLES}

Table 1. Damages to hospital buildings during the Saguenay earthquake........................... 30

Table 2. Analysis framework for hospital systems .................................................. 31

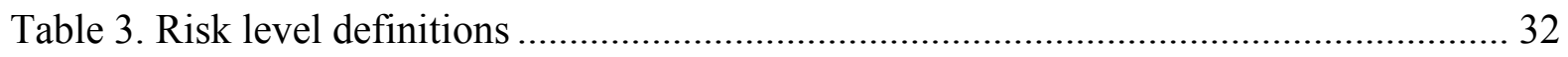


Table 1. Damages to hospital buildings during the Saguenay earthquake

Adapted from (Mitchell et al. 1990); Paultre et al. (1993)

\begin{tabular}{|c|c|}
\hline $\begin{array}{l}\text { Distance from epicentre } \\
\text { and accelerations }\end{array}$ & Observed damages in hospital buildings \\
\hline $\begin{array}{l}\text { Epicentral region } \\
(\mathrm{Hg}=0,156 \mathrm{~g} \\
\mathrm{Vg}=0,102 \mathrm{~g})\end{array}$ & Minor architectural damages \\
\hline $\begin{array}{l}150 \mathrm{~km} \text { from epicentre } \\
(\mathrm{Hg}=0,05 \mathrm{~g})\end{array}$ & $\begin{array}{l}\text { Significant non-structural damage to two hospitals in Quebec City due } \\
\text { to amplification by alluvial deposits } \\
\text { - Major cracking to exterior unreinforced masonry walls parallel to the } \\
\text { weaker direction of the building } \\
\text { - Collapse of two masonry chimneys } \\
\text { - Cracked plaster in lift shafts and corridors } \\
\text { - Derailment of an elevator shaft (lack of rigidity of the rails) } \\
\text { - Shear failure in the concrete beam supporting the rails of a lift (when } \\
\text { restarting the elevator) } \\
\text { - Shear failure in MNA walls between the openings } \\
\text { - Failure of the heating system radiator } \\
\text { - Power outage for two hours (dysfunction of the emergency generator) }\end{array}$ \\
\hline
\end{tabular}


Table 2. Analysis framework for hospital systems

Adapted from Rinaldi et al. (2001) et Limnios (1991)

\begin{tabular}{|c|c|c|c|c|}
\hline (Limnios & \multicolumn{2}{|c|}{ (Rinaldi et al. 2001) } & \multicolumn{2}{|c|}{ Proposed framework } \\
\hline Problem & Dimensions & $\begin{array}{c}\text { Elements of } \\
\text { interdependencies }\end{array}$ & Global objectives & Models \\
\hline \multirow{2}{*}{$\begin{array}{l}\text { What are the } \\
\text { failure modes } \\
\text { of system } \\
\text { components? }\end{array}$} & Type of failure & Common cause, cascading & \multirow{2}{*}{$\begin{array}{l}\text { Analyze the nature of } \\
\text { the disturbance and the } \\
\text { vulnerability and } \\
\text { fragility of system } \\
\text { components }\end{array}$} & \multirow[b]{2}{*}{$\begin{array}{l}\text { In situ conditions or } \\
\text { seismic vulnerability } \\
\text { and Probabilistic } \\
\text { model or fragility } \\
\text { functions }\end{array}$} \\
\hline & State of operation & $\begin{array}{l}\text { Normal, repair/restoration, } \\
\text { stressed/disrupted }\end{array}$ & & \\
\hline \multirow[t]{2}{*}{$\begin{array}{l}\text { How does the } \\
\text { system fail? }\end{array}$} & $\begin{array}{l}\text { Types of } \\
\text { interdependencies }\end{array}$ & $\begin{array}{l}\text { Geographic, logical, cyber, } \\
\text { physical }\end{array}$ & \multirow{2}{*}{$\begin{array}{l}\text { Define } \\
\text { interdependencies } \\
\text { between systems and } \\
\text { degree of coupling }\end{array}$} & \multirow{2}{*}{$\begin{array}{l}\text { Algebraic model: } \\
\text { Boolean operators } \\
\text {.AND., .OR. } \\
\text { (Fault tree analysis) }\end{array}$} \\
\hline & $\begin{array}{l}\text { Coupling and } \\
\text { response behavior }\end{array}$ & $\begin{array}{l}\text { Adaptive, inflexible, } \\
\text { loose/tight, linear/complex }\end{array}$ & & \\
\hline \multirow[t]{2}{*}{$\begin{array}{l}\text { How likely } \\
\text { the system } \\
\text { would be } \\
\text { dysfunctional? }\end{array}$} & Environment & $\begin{array}{l}\text { Social/political, technical, } \\
\text { legal/regulatory, economic, } \\
\text { health/safety, public/policy, } \\
\text { business }\end{array}$ & \multirow[t]{2}{*}{$\begin{array}{l}\text { Identify the } \\
\text { infrastructure (or } \\
\text { system) and its } \\
\text { exposure to danger. }\end{array}$} & \multirow[t]{2}{*}{$\begin{array}{l}\text { System } \\
\text { representation } \\
\text { models (FTA) }\end{array}$} \\
\hline & $\begin{array}{l}\text { Infrastructure } \\
\text { characteristics }\end{array}$ & $\begin{array}{l}\text { Organisational, operational, } \\
\text { temporal, spatial }\end{array}$ & & \\
\hline
\end{tabular}


Table 3. Risk level definitions

\begin{tabular}{|c|c|c|c|c|c|}
\hline \multirow{2}{*}{$\begin{array}{l}\text { Level of } \\
\text { risk }\end{array}$} & \multirow{2}{*}{$\begin{array}{c}\text { Normalized } \\
\text { rank }\end{array}$} & \multicolumn{2}{|r|}{ Structural SRI } & \multicolumn{2}{|r|}{ OFC SRI } \\
\hline & & Threshold & $\begin{array}{c}\text { Reference for risk level } \\
\text { threshold }\end{array}$ & Threshold & $\begin{array}{c}\text { Reference for risk level } \\
\text { threshold }\end{array}$ \\
\hline Slight & 0.1 & $\mathrm{SRI} \leq 2$ & \multirow{2}{*}{ (LeBoeuf and Nollet 2006) } & $\mathrm{SRI} \leq 16$ & \multirow{2}{*}{ CSA-S832-14 } \\
\hline Moderate & 0.3 & $2<$ SRI $\leq 10$ & & $16<$ SRI $\leq 64$ & \\
\hline High & 0.5 & $10<\mathrm{SRI} \leq 20$ & $\begin{array}{l}\text { Range for structures with } \\
\text { any geometric irregularities } \\
\text { except site E }\end{array}$ & $64<\mathrm{SRI} \leq 86$ & $\begin{array}{l}\text { Observations that are not } \\
\text { outliers (upper whisker } \\
\text { or } 95^{\text {th }} \text { percentile) }\end{array}$ \\
\hline Very high & 1.0 & $\mathrm{SRI}>20$ & $\begin{array}{l}\text { Small buildings with } \\
\text { irregularities (all sites) } \\
\text { All buildings Sites D and E }\end{array}$ & $\mathrm{SRI}>86$ & $\begin{array}{l}\text { Extreme values (outliers) } \\
\text { corresponding to range } \\
\text { for Sites D and E }\end{array}$ \\
\hline
\end{tabular}




\section{LIST OF FIGURES}

Figure 1. Hospital functional components

Figure 2. Distribution of 31 hospitals facilities on the Island of Montreal

Figure 3. Main distribution plan for case-study hospitals: a) MGH and b) RDPH

Figure 4. Distribution of structural SRI values

Figure 5. Distribution of non-structural SRI values

Figure 6. Fragility curves for drift-sensitive OFCs for special buildings with different height, low (L), medium (M), and high (H)

Figure 7. Fragility curves for acceleration-sensitive OFCs for special buildings

Figure 8. Heating system fault tree

Figure 9. Air conditioning system fault tree

Figure 10. Example of a) domestic supply water system and b) air filter system

Figure 11. Life support system fault tree

Figure 12. Deaggregated PFI for the structure (PFI=PRI)

Figure 13. Deaggregated PFI for HVAC system

Figure 14. Deaggregated PFI for life support system

Figure 15. Risk matrix for PFI interpretation 


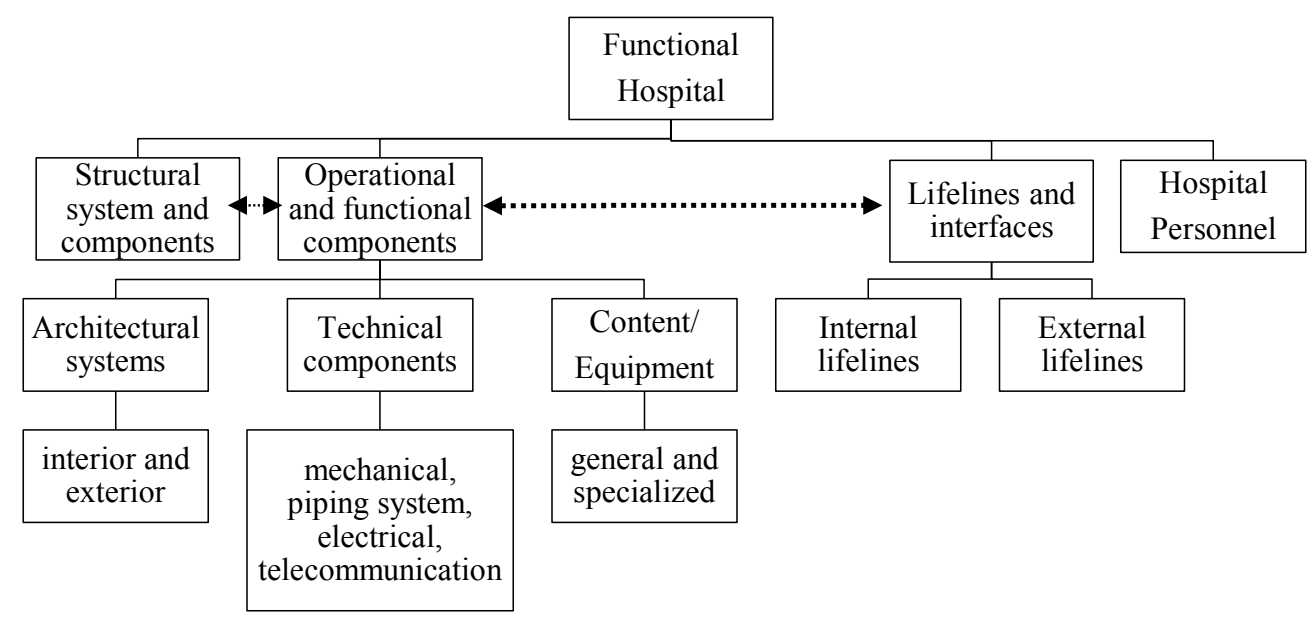




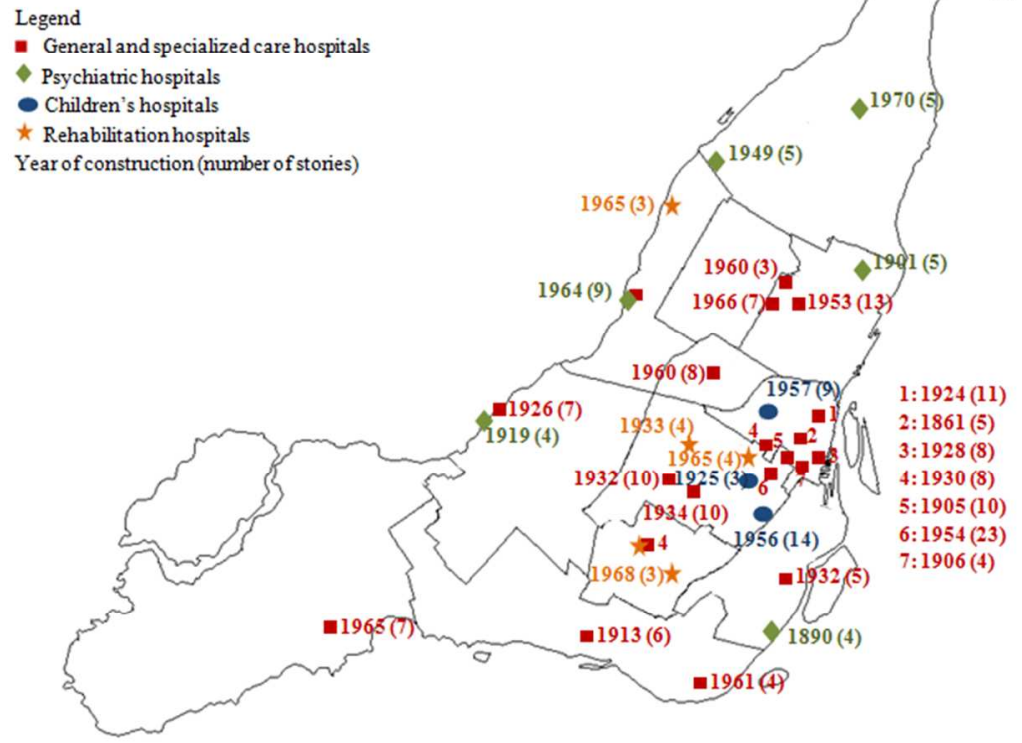



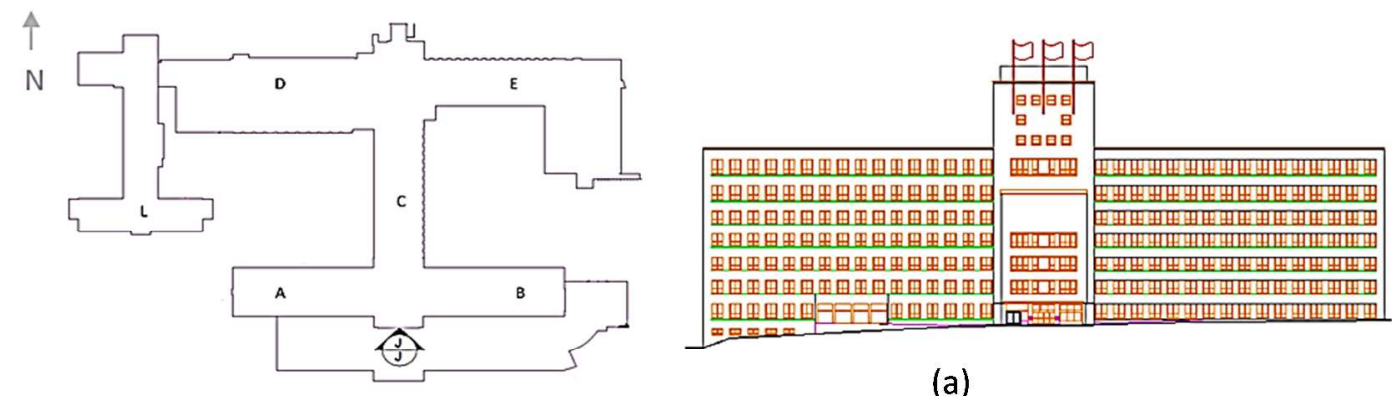

(a)
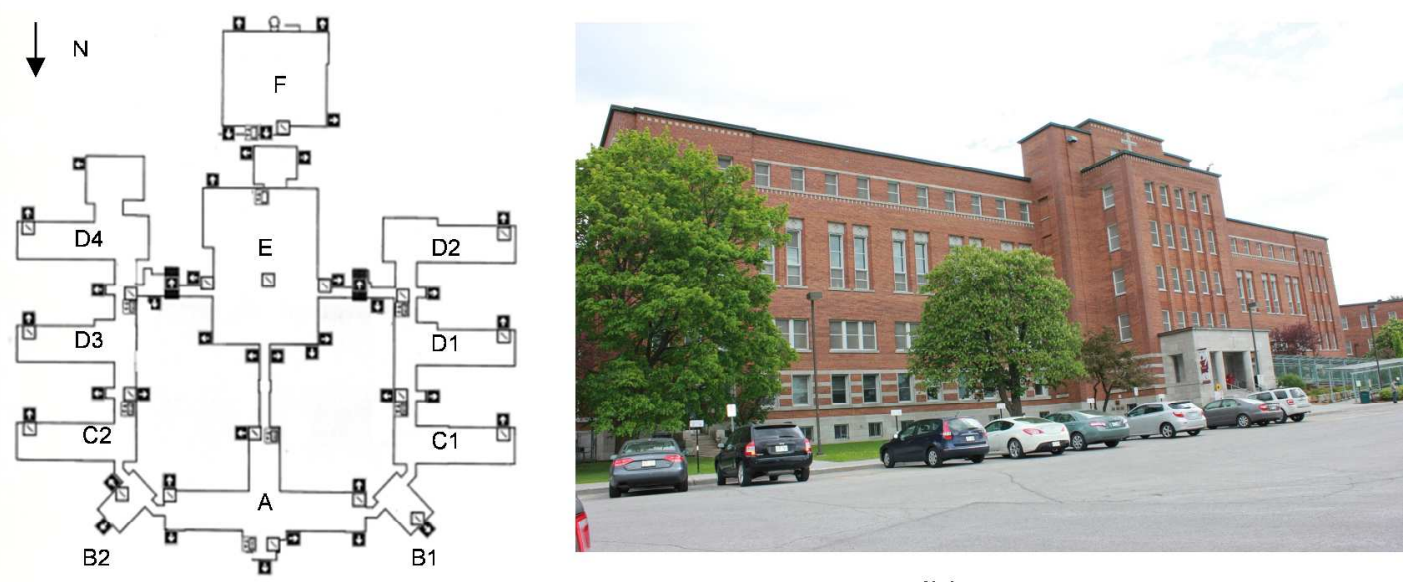

(b) 


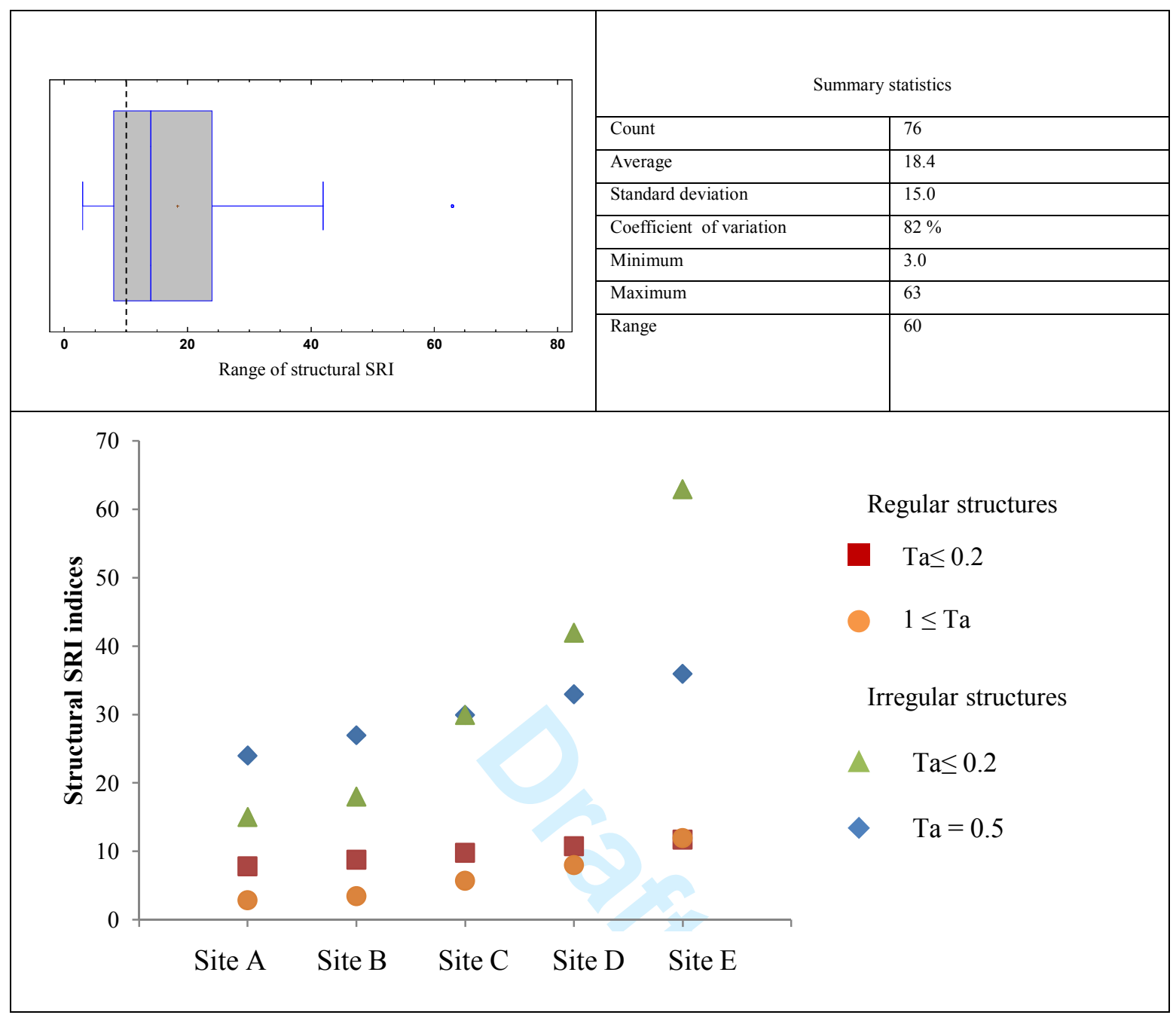




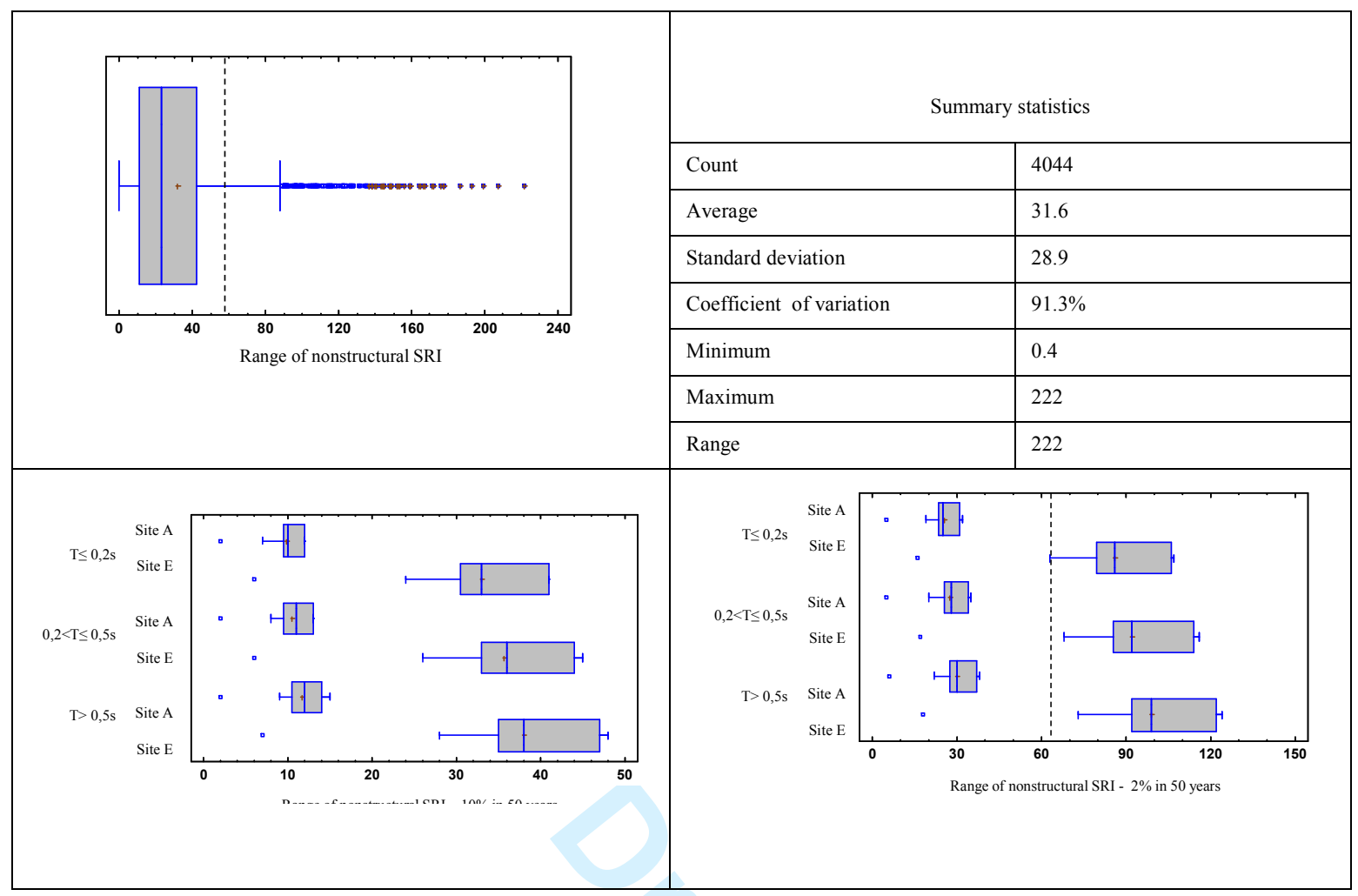




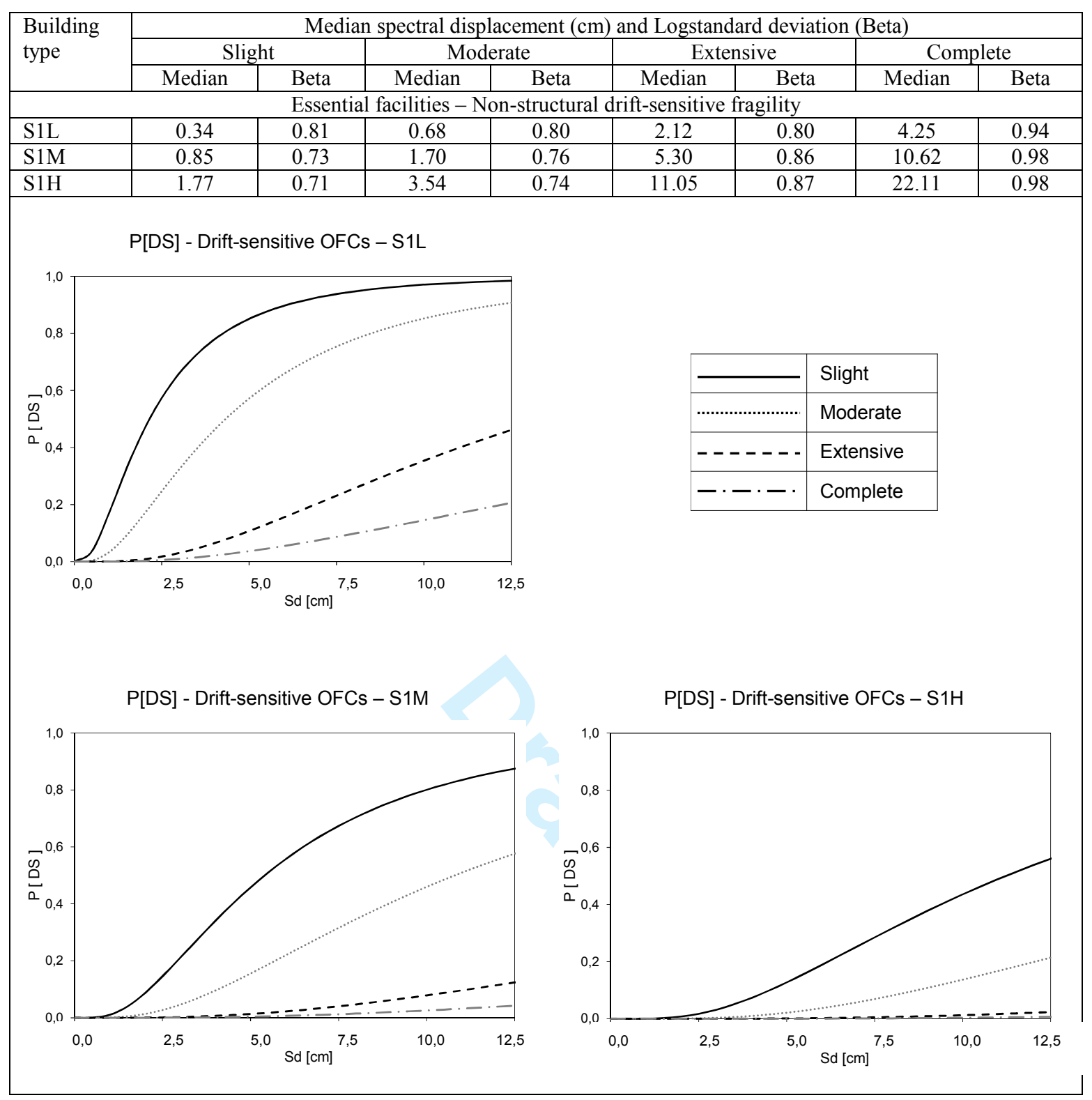




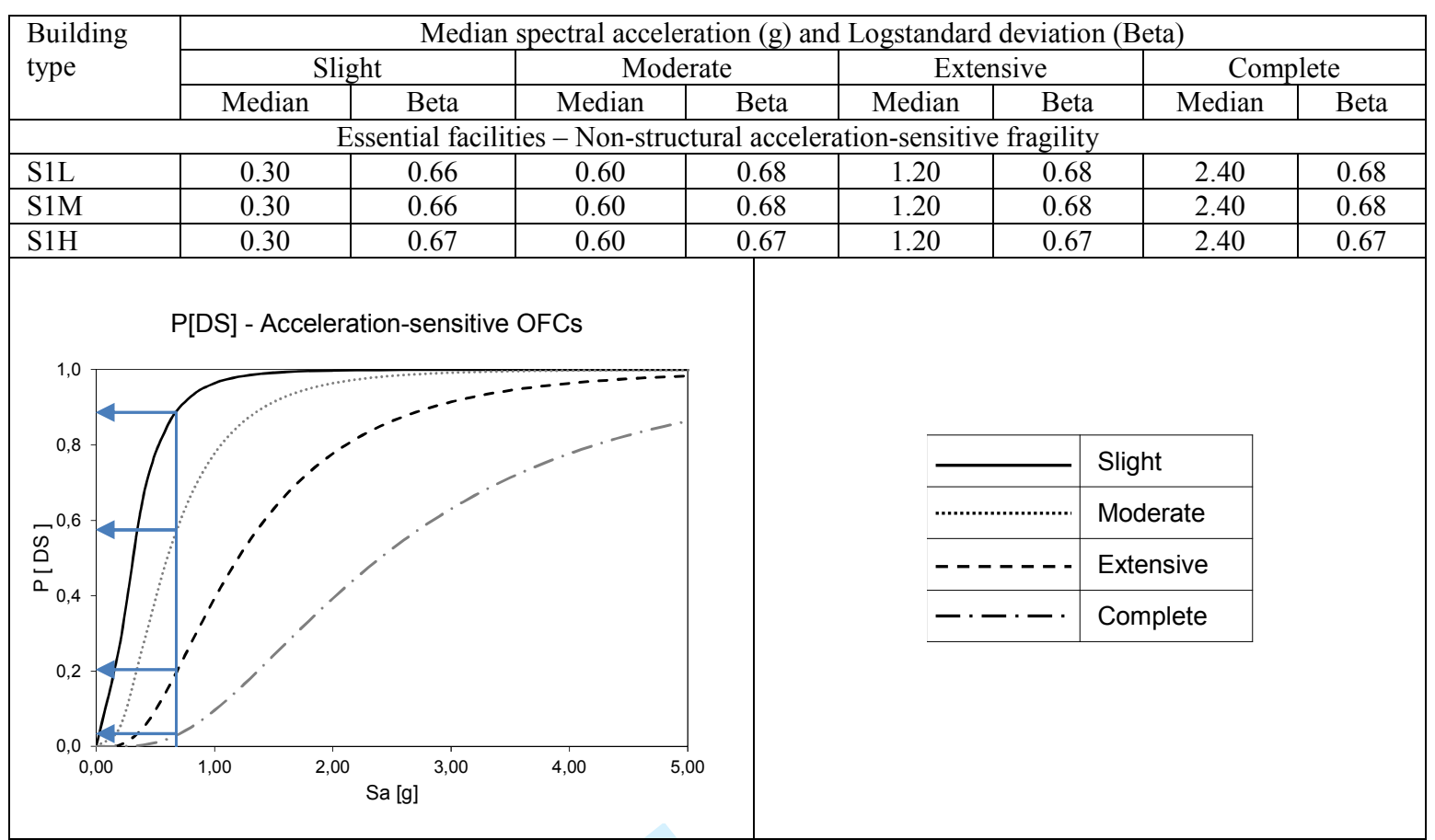




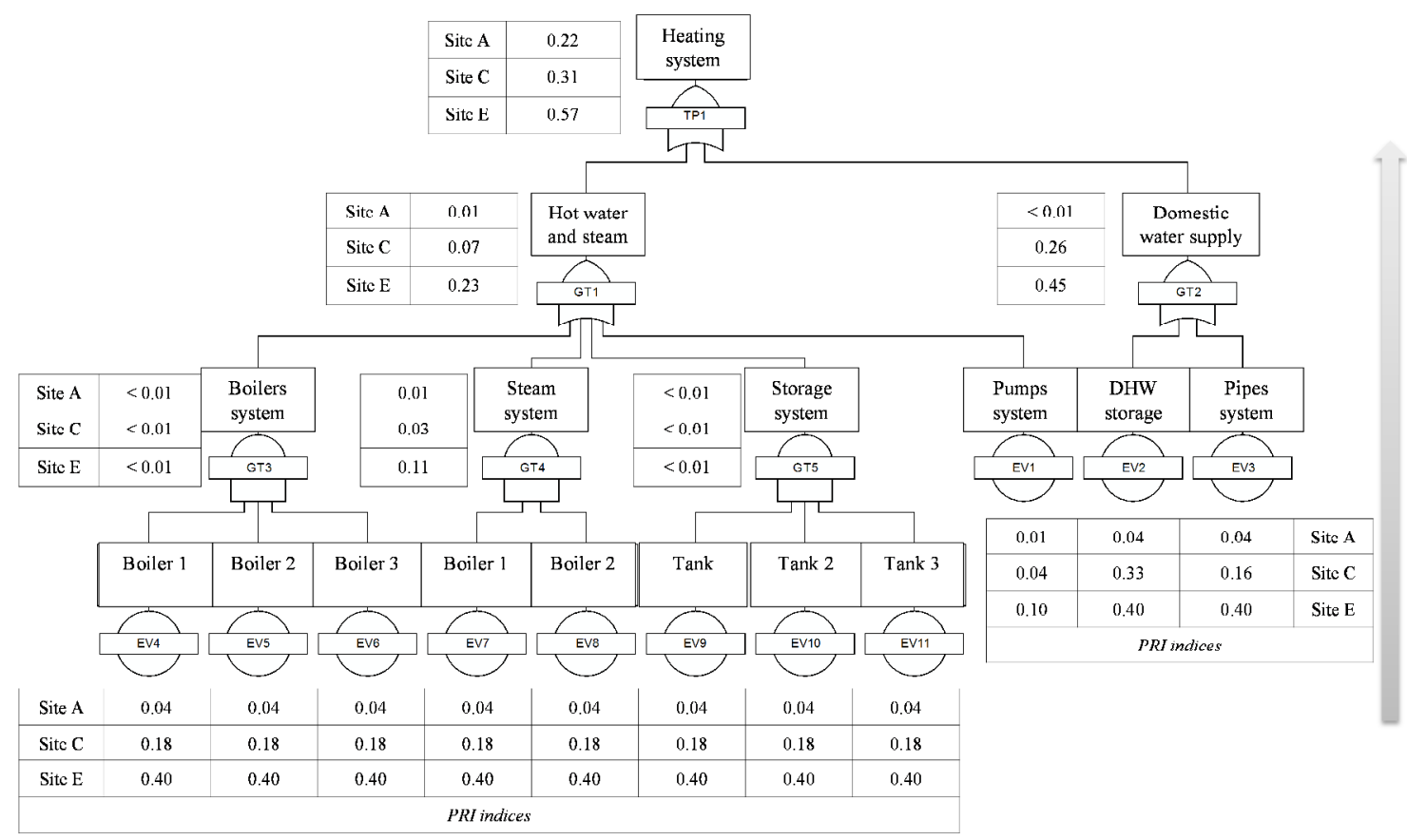




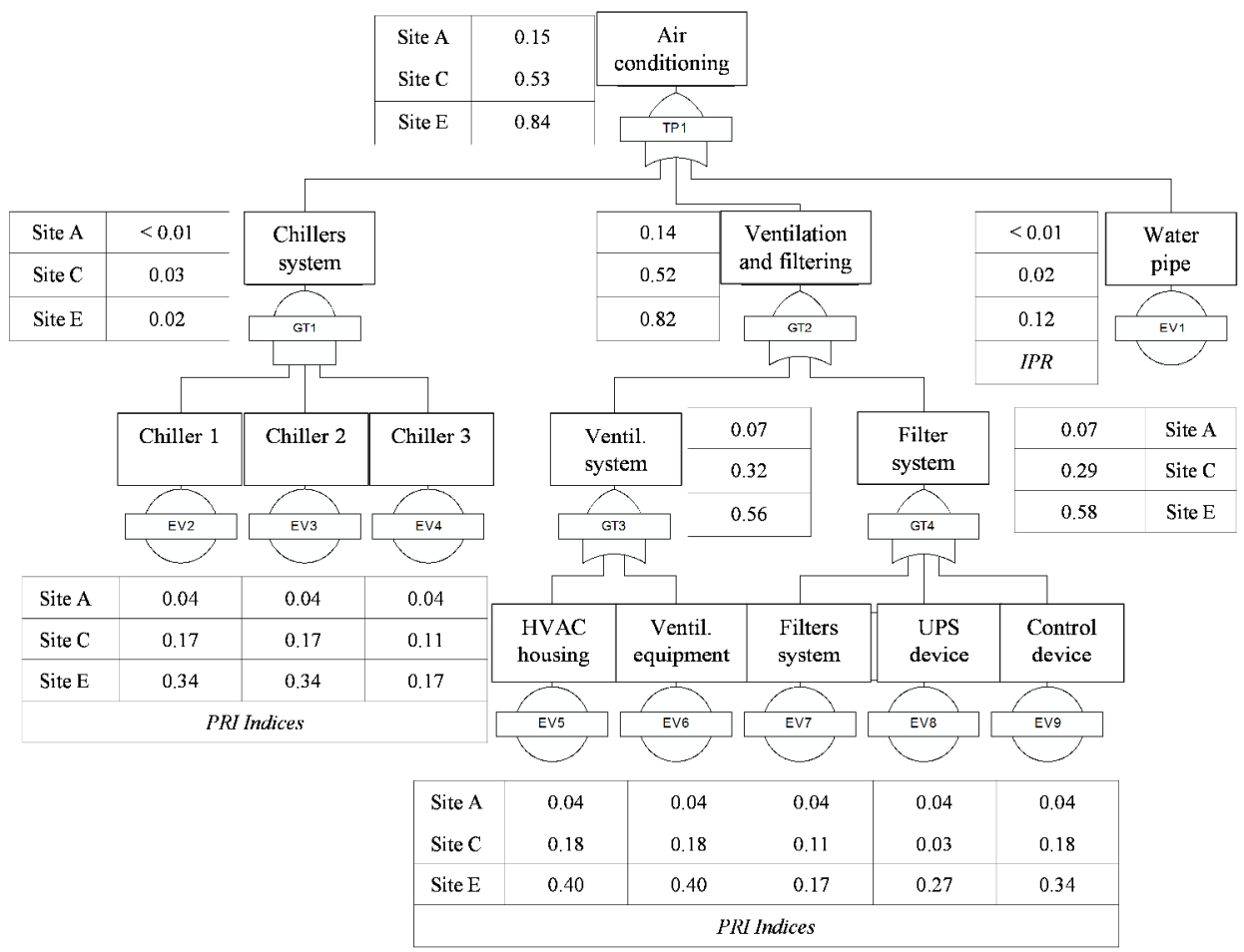



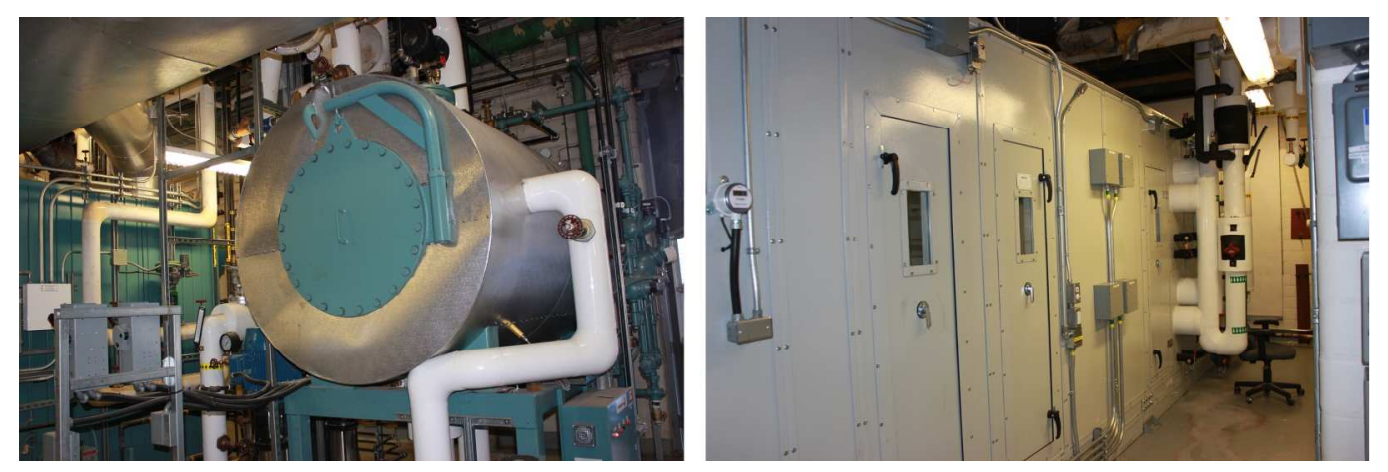


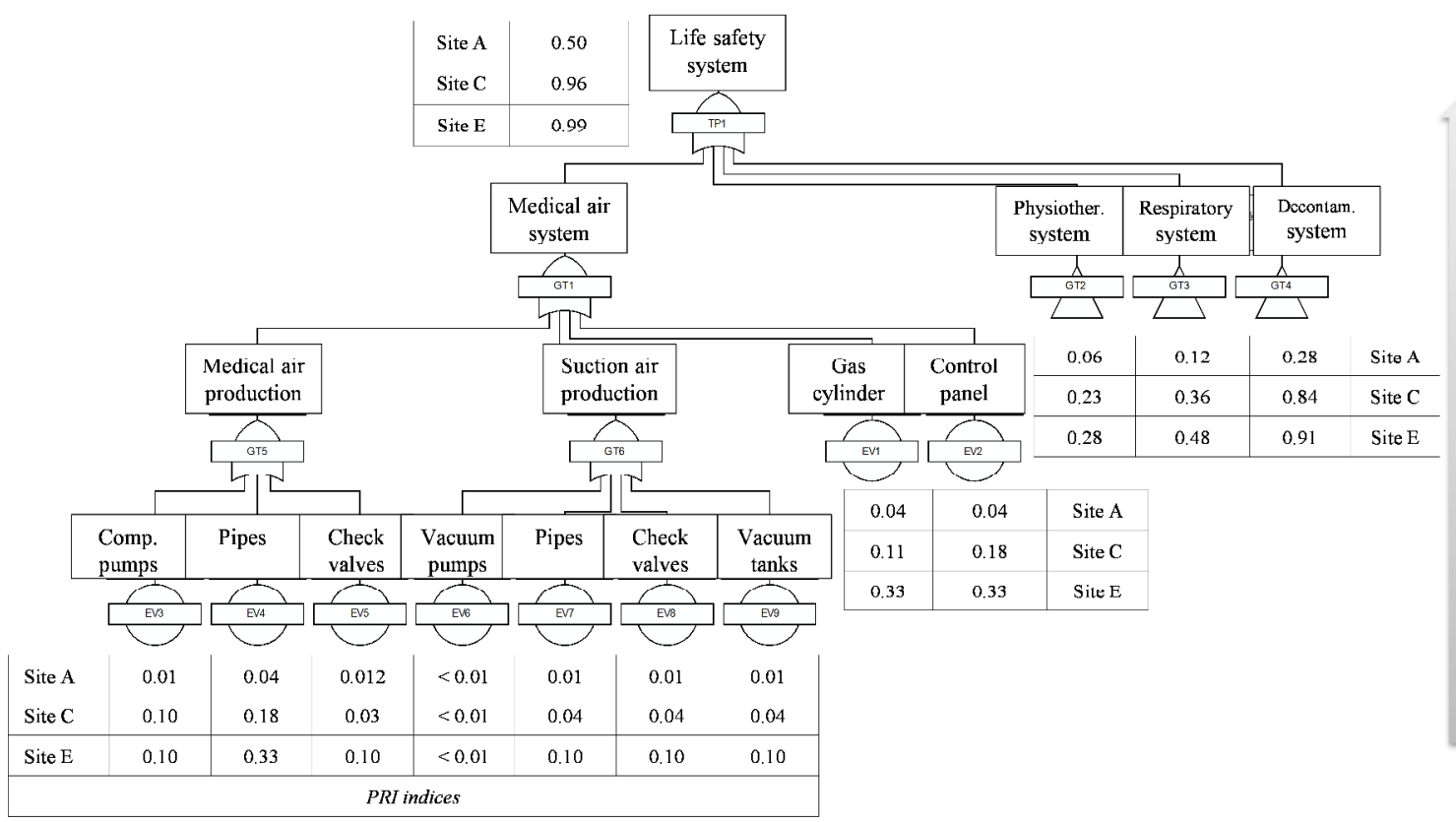




(1) 0,62s-10\% en 50 ans




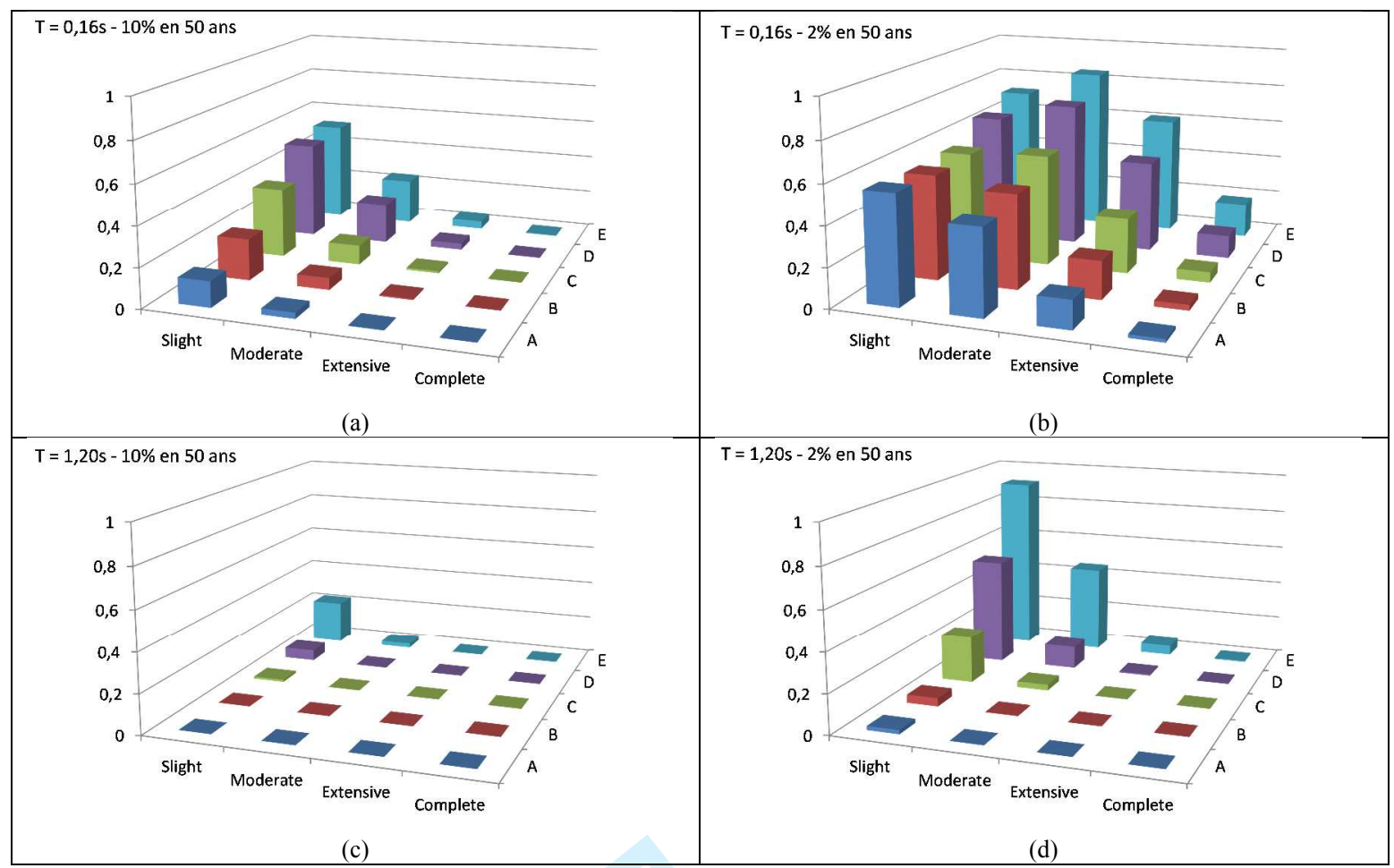




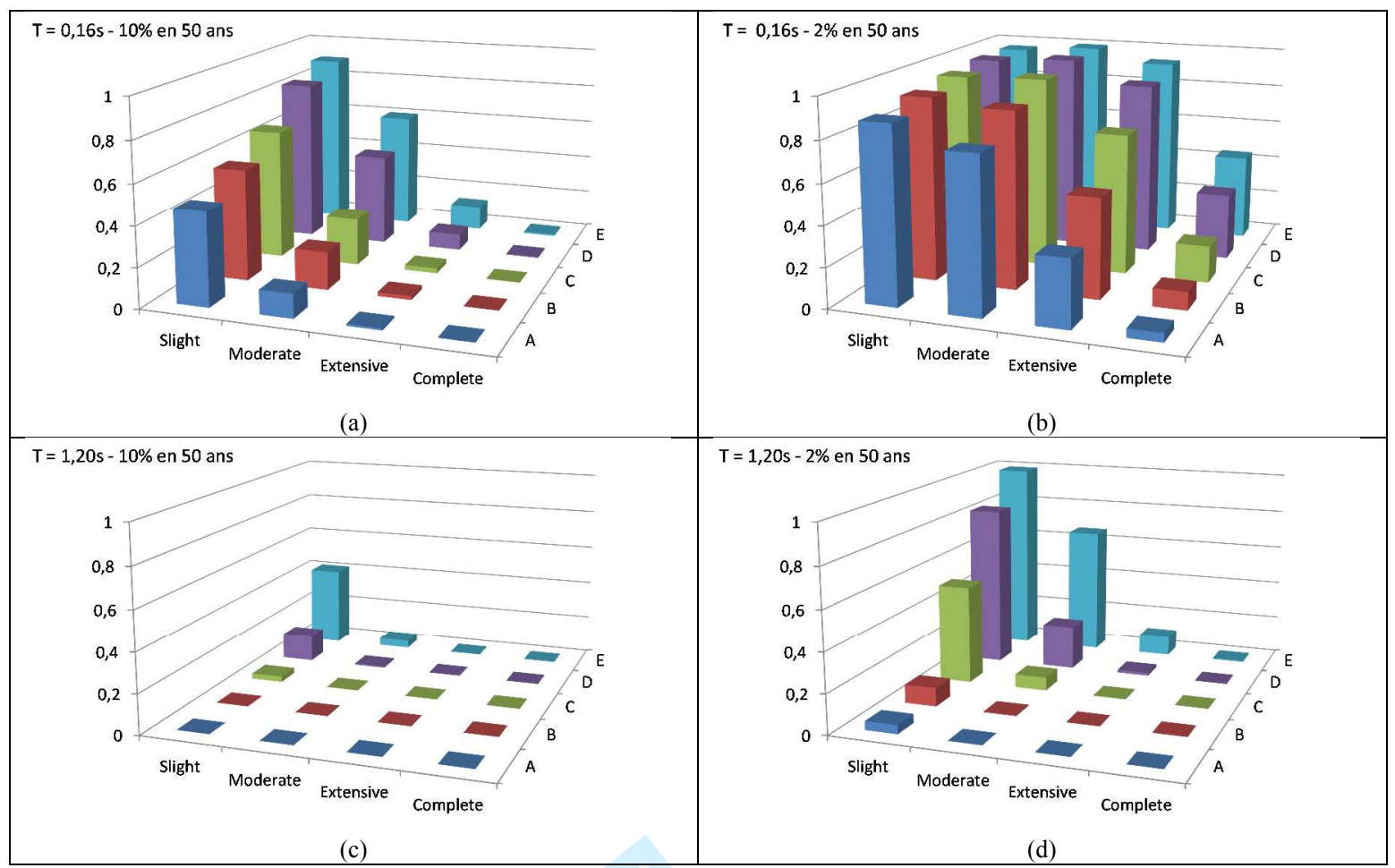




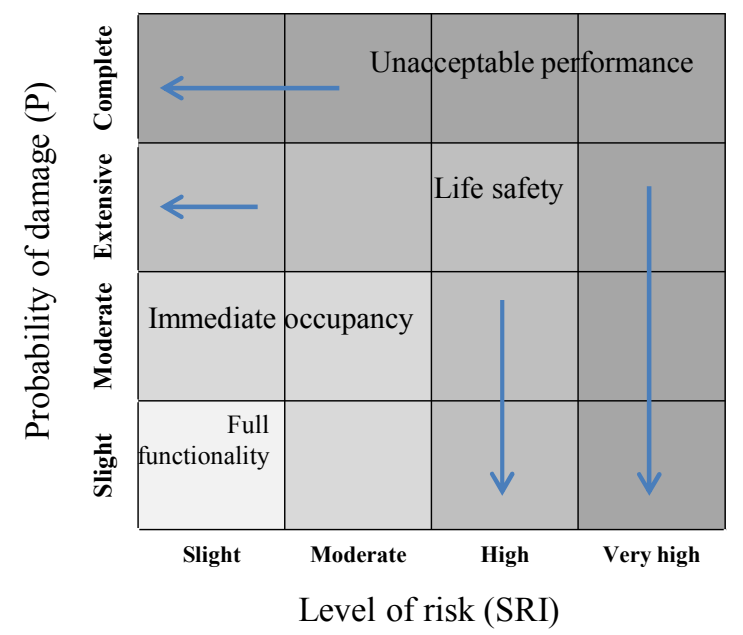

